\title{
SUTRADARA DJAKA HARJANTO PERTUNJUKAN HARDHASANGKARA WAYANG ORANG RRI SURAKARTA
}

\author{
Muhamad Alifi \\ Program Pascasarjana \\ Institut Seni Indonesia Surakarta \\ JI. Ki Hadjar Dewantara No. 19 Kentingan, Jebres, Surakarta, 57126
}

I Nyoman Murtana

ISI Surakarta

\begin{abstract}
ABSTRAK
Hasil penelitian menunjukkan bahwa sutradara wayang orang merupakan sebuah jabatan untuk mendidik, mengajar, membimbing, mengarahkan, melatih, menilai, dan mengevaluasi pertunjukan wayang orang. Sutradara fungsinya sebagai pendidik menyampaikan pengetahuan yang telah dimiliki kepada semua pemain. Figur seniman tradisi yang melekat pada diri Joko Harjanto karena profesionalisme yang dimiliki untuk melestarikan budaya tradisi wayang orang. Saat ini hiburan berkembang cukup pesat, mendobrak nilai budaya masyarakat. Figur seniman tradisi berperan aktif menyelamatkan dan kembali pada akar budaya pertunjukan wayang orang. Sesuai dengan semangat RRI Surakarta yang lebih mengutamakan nilai-nilai budaya yang sudah ada dimasyarakat dari pada menciptakan budaya baru dalam seni pertunjukan.
\end{abstract}

Kata kunci: Wayang Orang, Hardhasangkara, Sutradara.

\begin{abstract}
The results of the study show that the director of wayang orang is a position to educate, to teach, to guide, to direct, to train, to assess, and to evaluate the performances of wayang orang. The director functions as an educator conveys the knowledge that has been shared with all presenters. A traditional artist who is attached to Joko Harjanto because of the professionalism he has to preserve the culture of wayang orang traditions. At present entertainment is growing quite rapidly, breaking the cultural value of society. Traditional artist figures play an active role in saving and returning to the cultural roots of the wayang orang. It is In accordance with the spirit of RRI Surakarta which prioritizes the cultural values that already exist in the community rather than creating a new culture in the performing arts.
\end{abstract}

Keywords: Wayang Orang, Hardhasangkara, Director.

\section{A. Pengantar}

Sutradara wayang orang selalu memiliki ide dan misi setiap menyelenggarakan pertunjukan wayang orang. Ide yang digunakan sejajar dengan nilai-nilai yang terkandung dalam teater wayang orang. Sutradara Djaka Harjanto memberikan hubungan yang jelas agar ide pertunjukan wayang orang dengan nilai-nilai budaya Jawa tidak saling bertentangan. Saat ini panggung hiburan berkembang cukup pesat, tidak jarang mendobrak nilai budaya Jawa. Sebagai seorang sutradara wayang orang Djaka Harjanto ikut berperan menyelamatkan nilai budaya Jawa dengan menampilkan pertunjukan wayang orang.
Sutradara wayang orang menggunakan ide cerita lakon Hardhasangkara yang sesui dengan nilai-nilai budaya Jawa sebagai sarana untuk melatih kemampuan para pemainnya. Sutradara mengamati penampilan para aktornya mulai dari berlatih sampai selesai pertunjukan wayang orang agar bisa memberikan masukan dalam pertunjukan selanjutnya.

Aktor wayang orang RRI Surakarta sangat menyadari tentang tugas sutradara wayang orang yang sering memberikan masukan karena sebagai pengendali pertunjukan seni. Sutradara mengendalikan para pemain wayang orang agar teratur saat pertunjukan, mudah dinikmati dan sesuai dengan nilainilai budaya Jawa. 


\section{GEEAR Jumal Sari iuduya}

Sutradara wayang orang merupakan sebuah jabatan untuk mendidik, mengajar, membimbing, mengarahkan, melatih, menilai, dan mengevaluasi pertunjukan wayang orang. Sutradara wayang orang RRI Surakarta Djaka Harjanto memiliki tahapan kerja yang rinci. Tahapan kerja sutradara di antaranya memilih balungan lakon, penuangan, casting, latihan, dan pertunjukan wayang orang. Jabatan sutradara wayang orang dan tahapan kerja yang teratur menjadikan nilai dominasi semakin tinggi. Nilai otoritas saat memberikan pengarahan kepada aktornya tidak mungkin berkurang saat tahapan kerja dan jabatan sebagai sutradara dipegang sebaik mungkin.

Sutradara wayang orang RRI Surakarta era Djaka Harjanto lebih cenderung pada profesi kerja. Nilai otoritas yang dimunculkan oleh sutradara wayang orang menjadi media pelatihan bagi para pemain. Sutradara wayang orang Djaka Harjanto cenderung menggunakan fungsinya sebagai pendidik. Sutradara menyampaikan pengetahuannya kepada semua pemain. Banyak pemain wayang orang RRI Surakarta yang memiliki kemampuan akademis tinggi dan mahir menari, tetap menghargai sutradara karena menilai sebagai mitra dalam bekerja.

Sutradara wayang orang RRI Surakarta harus lebih mengutamakan nilai-nilai budaya yang sudah ada. Inovasi dan kreasi baru dalam pertunjukan wayang orang sangat disinergikan dengan nilai pertunjukan yang sudah dipelajari oleh sutradara. Semangat untuk mengubah dan merevolusi kesenian wayang orang tidak dimiliki oleh sutradara Djaka Harjanto, sehingga inovasi pada pertunjukan wayang orang RRI Surakarta tidak cukup mencolok. Profesionalisme utama dari sutradara wayang orang Djaka Harjanto sebagai figur seniman tradisi dan melestarikan budaya tradisi.

Sutradara teater modern lebih cenderung pada kreator dan inovator untuk mengikuti perkembangan zaman, berbeda dengan sutradara wayang orang Djaka Harjanto kompetisi kreatif dipahaminya secara bijaksana, sifat dinamis akan selalu ada, perubahan boleh terjadi, akan tetapi tidak boleh merubah esensi tradisi wayang orang. Sikap bijak sutradara Djaka Harjanto dalam menghadapi perubahan seni pertunjukan secara global saat ini yaitu tidak mudah terpengaruh dengan bentuk kesenian lain. Kesadaran dalam bermain wayang orang telah dimiliki para seniman wayang orang RRI Surakarta. Kualitas kesenian yang menunjukkan pada pemahaman tentang talenta berkesenian dengan nilai-nilai tradisi tetap menjadikan seni pertunjukan wayang orang yang terbaik. Para seniman wayang orang telah memiliki motivasi yang sangat kuat dalam mempertahankan seni pertunjukan wayang orang.

\section{B. Peran Sutradara Sebagai Pendidik}

Sutradara pertunjukan wayang orang RRI Surakarta Djaka Harjanto lebih cenderung mendidik nilai-nilai budaya dari pada inovasi pertunjukan. Pendidikan yang ditekankan oleh sutradara Djaka Harjanto cenderung bersifat meningkatkan seni budaya wayang orang yang sudah ada. Mendidik agar tetap berpegang teguh pada bentuk kesenian yang sudah ada merupakan tugas yang sangat berat bagi seorang sutradara. Menekan pemain wayang orang agar tetap fokus pada nilai-nila budaya dan tidak membawa budaya yang lain muncul di atas panggung wayang orang RRI Surakarta.

Hasil dari pendidikan yang ditekankan oleh sutradara Djaka Harjanto untuk mempertahankan nilainilai budaya adalah penjiwaan para pemain wayang orang terhadap tokoh-tokoh yang sangat diidolakannya. Kemampuan pemain terus meningkat saat memainkan tokoh-tokoh yang sangat diidolakan. Jika kemampuan para pemain terlihat mulai menurun maka sutradara Djaka Harjanto mencoba menciptakan perubahan casting peran.

Hasil baik dari perubahan casting peran dialami oleh Dedek Djarwadi saat berperan menjadi tokoh Semar pada pertunjukan wayang orang RRI Surakarta dengan judul Hardhasangkara. Dedek Djarwadi ingin memerankan tokoh Semar pada pertunjukan wayang orang yang selanjutnya. Dedek Djarwadi terlihat nyaman dengan karakter sebagai Semar pada pertunjukan wayang orang dengan judul Hardhasangkara. Sejak lama Dedek Djarwadi bermain karakter tokoh wayang sebagai Raden Werkudara, rasa ingin berganti karakter terpenuhi saat bermain wayang orang dalam lakon Hardhasangkara.

Hasil peningkatan yang sangat signifikan di alami oleh Joko Sudiyana, sejak lama berperan sebagai Gareng, pada pertunjukan ini Joko Sudiyana berganti peran menjadi Prabu Hardhasangkara. Joko Sudiyana mengalami berbagai macam kesulitan saat latihan terutama saat sinkronisasi tembang dan tari. Perkembangan yang dialami Joko Sudiyana pada pertunjukan dimulai, sangat bagus bahkan banyak penonton yang ikut mengapresiasi pertunjukan sebagai Prabu Hardhasangkara. 


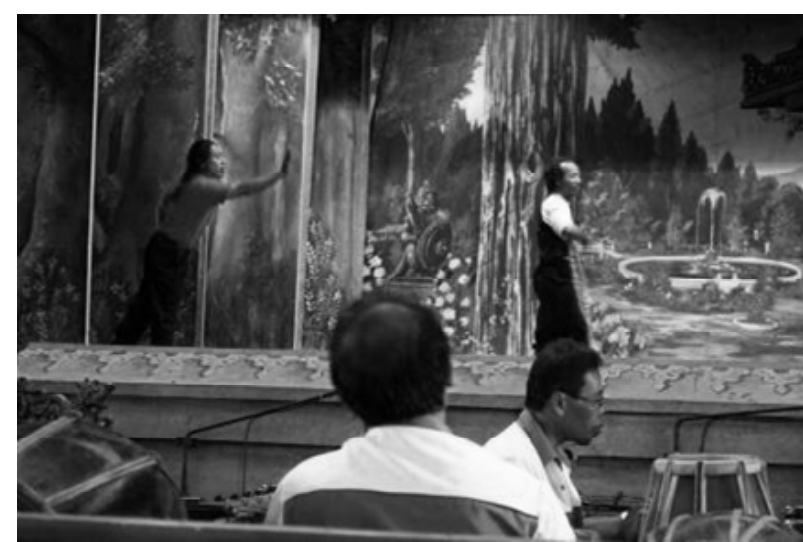

Gambar 1. Latihan wayang orang, sutradara Djaka Harjanto sedang memberi arahan pada pemainnya.

(Foto M.Alifi, 2012)

Pendidikan inovasi yang diterapkan sutradara Djaka Harjanto berjalan cukup baik pada sebagian para pemain wayang orang RRI Surakarta. Pendidikan agar terus mempertahankan nilai-nilai budaya, tanpa merubah budaya yang sudah ada. Kejenuhan para pemain terobati saat dipaksa lebih memahami karakter tokoh wayang orang yang lain dan memerankannya. Inovasi casting tokoh wayang orang, sebagai penghibur dan pendidikan, dianggap berharga bagi sebagian para pemain wayang orang. Dianggap wajar jika inovasi casting tokoh wayang orang saat lakon Hardhasangkara menurun kualitasnya dengan pertunjukan yang sebelumnya. Sutradara Djaka Harjanto menganggap kualitas pemain wayang orang ditentukan oleh intensitas belajar, jika pemain tidak diberi ruang untuk mencoba maka kegiatan untuk memberikan pendidikan pada pemain tidak akan pernah tercapai.

Intensitas pendidikan pemain untuk menjadi tokoh wayang orang dipengaruhi dengan semangat pemain wayang orang. Sutradara Djaka Harjanto menangkap bahwa Joko Sudiyana mampu memainkan tokoh utama yaitu Prabu Hardhasangkara. Semangat yang dimiliki Joko Sudiyana untuk berlatih sangat kuat, diimbangi dengan kemampuan catur yang mahir membuat sutradara Djaka Harjanto memberi kesempatan casting peran utama menjadi Prabu Hardhasangkara. Pendidikan menjadi tokoh wayang orang merupakan kegiatan wajib bagi para pemain wayang orang RRI Surakarta, tidak menjadi alasan jika pendidikan menjadi tokoh wayang orang tidak dapat diteruskan karena kemampuan pemain. Pertunjukan wayang orang harus terus berjalan karena telah menjadi profesi bagi para pemain wayang orang RRI Surakarta.
Pendidikan yang diberikan sutradara Djaka Harjanto merupakan kegiatan untuk membentuk jati diri para pemain, bersemangat, memiliki motivasi kuat, dan memiliki kemampuan dalam pertunjukan wayang orang. Pendidikan yang diberikan merupakan ilmu praktis yang harus senantiasa dilatih sendiri oleh pemain wayang orang. Pemain wayang orang RRI Surakarta sebagai pemain profesional harus menguasai banyak cerita, karena sewaktu-waktu akan dimainkan di atas panggung. Penguasaan ide cerita wayang orang, penguasaan bahasa, penguasaan tari dan penguasaan tembang menjadi pendidikan berharga bagi para pemain wayang orang.

Pendidikan dan motivasi yang diberikan oleh sutradara bertujuan untuk meningkatkan mutu permainan wayang orang. Pertunjukan wayang orang selain memiliki mutu yang baik, juga didasarkan pada semangat, serius, mudah ditangkap, dan membangkitkan rasa humor yang baru. Motivasi yang diberikan oleh sutradara Djaka Harjanto bertujuan untuk pemain, pemain mampu memerankan berbagai jenis karakter tokoh wayang orang, apapun yang sedang dibutuhkan dan diinginkan sutradara.

Pendidikan yang diberikan sutradara wayang orang Djaka Harjanto memiliki perbedaan dengan nilainilai yang diterapkan Rusman. Tertulis dalam buku yang berjudul Rusman Antara Maknit Bung Karno dan Karisma Gathutkaca; Wayang Orang Sriwedari menerangkan sebagai berikut, menurut Asmarahadi, penari rol identik dengan kepemimpinan budaya yang mampu mendinamisasikan kehidupan grup wayang wong. la mempunyai wewenang dalam grup, bahkan manajer dan sutradara (Harsapandi, 2011: 98). Pendidikan yang ditekankan oleh sutradara Djaka Harjanto kepada para pemain tentang penghormatan pada konvensi-konvensi dari nilai-nilai tradisi yang telah disepakati.

Dominasi otoritas dan kharisma Rusman selama 48 tahun sebagai penari tokoh Gathutkaca tampaknya sulit ditembus karena proteksi diri dan ia tidak menciptakan penggantinya (Harsapandi, 2011: 232). Dominasi sutradara wayang orang Djaka Harjanto berbeda dengan otoritas yang dimiliki Rusman. Rusman tidak pernah mau menciptakan pesaing dan pengganti dirinya sebagai penari rol. Dominasi otoritas Rusman yang kuat menyebabkan kekosongan penerusnya sebagai penari rol. Sebaliknya yang dilakukan oleh sutradara Djaka Harjanto pada saat latihan lakon Hardhasangkara. Djaka Harjanto sebagai sutradara cenderung memberikan kesempatan kepada pemain muda yang berbakat untuk tampil lebih lama di atas panggung. Djaka Harjanto menganggap bahwa 


\section{GEEAR Jumal sai isudya}

pemain muda yang berbakat merupakan mitra kerja yang dapat diandalkan sewaktu-waktu ada kekosongan pemain inti.

Sutradara dibebani banyak tugas yang tidak mungkin dapat diselesaikan secara pribadi. Kerja sama yang baik harus dijaga dengan pemain wayang orang yang lain. Memberikan pelajaran tentang konvensikonvensi pertunjukan wayang orang kepada pemain muda merupakan tanggung jawabnya. Bagi Djaka Harjanto memberikan pelajaran pada mitra kerja merupakan keuntungan, dapat meringankan beban, menjadi pengganti dirinya sewaktu-waktu dan regenerasi.

Pelajaran yang diberikan sutradara Djaka Harjanto pada pemain wayang orang ditekankan pada pembuatan pertunjukan wayang orang berjalan dengan baik dan lancar. Pelajaran yang diberikan sutradara Djaka Harjanto saat latihan wayang orang dengan lakon Hardhasangkara merupakan kegiatan yang menarik karena perubahan casting dengan alasan regenerasi pemain. Pengolahan regenerasi pemain yang dilakukan Djaka Harjanto secara mendadak melakukan perubahan kesting untuk menguji kesiapan pemain. Pelajaran berharga bagi Joko Sudiyana yang telah diberi ruang lebar di atas panggung untuk menjadi peran utama yaitu Prabu Hardhasangkara.

Para pemain terkadang memiliki ide yang sangat liar dalam pertunjukan wayang orang, sutradara memberikan ruang bermain di atas panggung selama kreasi para pemain tidak bertentangan dengan nilainilai budaya. Sutradara menyatukan ide-ide para pemain wayang orang dalam wujud pertunjukan yang menarik. Pemain wayang orang dibebaskan merangkai kata-kata dalam catur tentang nilai filsafat, nilai politik, hukum, budaya, dan pendidikan. Kebebasan yang diberikan oleh sutradara Djaka Harjanto dalam pertunjukan wayang orang dengan lakon Hardhasangkara, merupakan kebebasan dalam merangkai kata (catur). Para pemain wayang orang diberikan waktu untuk mengungkapkan kegelisahan yang mereka alami di atas panggung menggunakan karakter tokoh wayang orang yang mereka mainkan.

Sutradara wayang orang Djaka Harjanto memaknai panggung sebagai tempatnya mendidik. Panggung pertunjukan sebagai ruang yang telah ditata sedemikian baik untuk media pendidikan tentang penjiwaan tokoh, ekspresi tokoh, dan suasana cerita wayang orang. Sutradara wayang orang Djaka Harjanto mendidik para pemain dengan nilai-nilai dasar pertunjukan lakon Hardhasangkara. Pendidikan yang ditekankan sutradara pada para pemain wayang orang lakon Hardhasangkara di antaranya berhubungan dengan situasi masyarakat, kondisi, isu politik, dan budi pekerti.

Sutradara wayang orang Djaka Harjanto memilih lakon sering kali berhubungan dengan nilai moral dan budi pekerti. Bagi Djaka Harjanto nilai moral dan budi pekerti dapat memberikan kepuasan batin . Nilai budi pekerti yang diinginkan Djaka Harjanto berhubungan dengan seni, pendidikan, hiburan dan yang bermanfaat untuk kesucian batin. Selain pelajaran tentang budi pekerti sutradara Djaka Harjanto juga menekankan pada nilai estetika. Penilaian tentang estetika dimulai dari struktur cerita, gaya bahasa lakon, kejiwaan lakon, tindakan penyelesaian lakon. Sutradara Djaka Harjanto juga memberi pelajaran pada para pemain tentang nilai keindahan dalam pertentangan, kejiwaan dan tindakan yang tepat saat di atas panggung.

Bagi sutradara tahap latihan ini adalah tahap membimbing pemain, dan mempersiapkan mereka untuk tampil dalam pertunjukan. Pemain wayang orang harus banyak memiliki inisiatif dan tindakan yang tepat saat di atas panggung. Tahapan pertunjukan wayang orang suatu peristiwa yang ditunggu-tunggu, sangat penting bagi sutradara Djaka Harjanto dan para pemainnya. Sutradara Djaka Harjanto menginginkan pertunjukan wayang orang dapat berisi tentang petuah moral untuk mencapai tingkat pencerahan bagi para pemain dan penonton.

\section{Peran Sutradara Sebagai Pembimbing}

Banyak cara yang dilakukan sutradara Djaka Harjanto untuk membimbing para pemain wayang orang. Djaka Harjanto memiliki dasar yang kuat sebagai seorang penari, peran utamanya sebagai seorang sutradara dilakukan dengan cara membimbing tari dan catur. Gerak tari yang diinginkan sutradara Djaka Harjanto adalah yang memiliki makna dalam hidup, biasa memadukan gerak, kehati-hatian, dan selalu waspada terhadap lawan main, itu semua menjadi nilai bimbingan yang diutamakan. Gerak tubuh pemain wayang orang memiliki maksud, bentuk, berirama, dan bermakna. Sutradara Djaka Harjanto memberi keyakinan para pemain wayang orang bahwa gerak pemain dalam menari di atas panggung sangat dibutuhkan untuk berkomunikasi pada para penonton. Penari wayang orang harus mahir memadukan dan merasakan irama, hati-hati dan waspada.

Djaka Harjanto memberikan motivasi kepada para pemain agar terus berkembang. Berbagai motivasi digunakan untuk merangsang semangat pemain wayang orang. Motivasi yang diberikan Djaka Harjanto 
selaku sutradara, pada Joko Sudiyana pemain tokoh Hardhasangkara merupakan motivasi yang bersifat tekanan, untuk mencoba bermain menjadi tokoh utama. Djaka Harjanto memilih Joko Sudiyana sebagai tokoh Hardhasangkara karena kemampuan catur yang baik dan kekuatan tarinya yang cukup baik untuk dikembangkan lagi. Djaka Harjanto memilih pemain wayang orang berdasarkan kekuatan motivasi yang mendorong diri, timbulnya semangat untuk maju, dihargai penonton atau komunitas sesuai dengan kemampuannya.

Sutradara memiliki keyakinan bahwa keberhasilan sajian wayang orang tidak hanya ditentukan oleh unsur nilai artistik gerak, tetapi dapat dilihat secara keseluruhan yaitu menyangkut segi kejiwaan dan tutur kata pemain tokoh wayang. Segi kejiwaan pemain mulai dibentuk dari unsur catur yang selalu ditekankan berkaitan dengan ketulusan, moralitas, pendidikan, dan kebudayaan. Dari segi pemilihan kata pemeran tokoh sentral wayang orang diwajibkan memiliki semangat, ketangkasan dalam dialog dan tembang. Pemilihan kata yang tepat, menceritakan tentang pendidikan, moralitas, dan kebudayaan untuk meningkatkan suasana pertunjukan. Pemahaman tentang level bahasa, level kalimat sangat mendukung kemampuan pemain wayang orang agar selalu sadar perilakunya di atas pentas. Mempelajari level bahasa sejajar dengan level tokoh untuk membimbing pemain wayang orang agar sadar saat bermain pada level tertentu.

Catur secara umum menunjukkan tingkat level tokoh wayang orang, penggunaan kata, penggunaan bahasa, penggunaan kalimat, dan gaya bahasa untuk menunjukkan level tokoh yang diperankan. Catur secara umum difungsikan untuk menyampaikan persoalan kepada para penonton dengan intonasi nada, ritme suara, pola suara, dialek tokoh, artikulasi tokoh dan lagu. Sutradara Djaka Harjanto menekankan pentingnya menggunakan catur, secara sesuai, tepat asas, relevan.

Sutradara Djaka Harjanto memberi pengarahan tentang catur wayang harus sesuai dengan status dan sosial tokoh tersebut saat dimainkan. Catur yang baik berarti perkataan yang tepat sasaran, mengungkapkan kalimat secara menjiwai, ekspresif, emosi, dan narasi harus tepat. Bekal catur yang baik untuk mengungkapkan kalimat secara tepat adalah pengetahuan lingkungan, wawasan, kecermatan, dan dapat merangkai kata secara benar. Sutradara Djaka Harjanto juga menegaskan para pemain wayang orang harus memiliki kemampuan menghafal sejarah tokoh wayang orang, negeri kekuasaan tokoh wayang tersebut, kelahiran tokoh wayang, tempat tokoh belajar, nama guru, nama istri tokoh, dan nama anak-anak keturunannya.

Pada latihan pertunjukan wayang orang yang berjudul Hardhasangkara, Sutradara Djaka Harjanto melakukan pembimbingan terhadap Joko Sudiyana untuk selalu mengendalikan diri, menjaga tingkah laku pribadi, menghilangkan tingkah laku Gareng agar tidak tercampur pada pertunjukan Hardhasangkara. Joko Sudiyana ditugaskan menunjukkan potensi dirinya, permainannya, dan kelebihan yang dimilikinya.

Pembimbingan yang dilakukan sutradara Djaka Harjanto untuk menjadikan pemain wayang orang menjadi tokoh yang sangat berbeda tingkah laku dari dirinya sendiri. Menjaga akting di atas panggung agar tidak tercampur dengan kebiasaan diri sangatlah sulit, maka Djaka Harjanto menegaskan harus disadari oleh setiap pemain wayang orang, dengan keyakinan bahwa semua yang dilakukan di atas panggung adalah akting seperti tokoh.

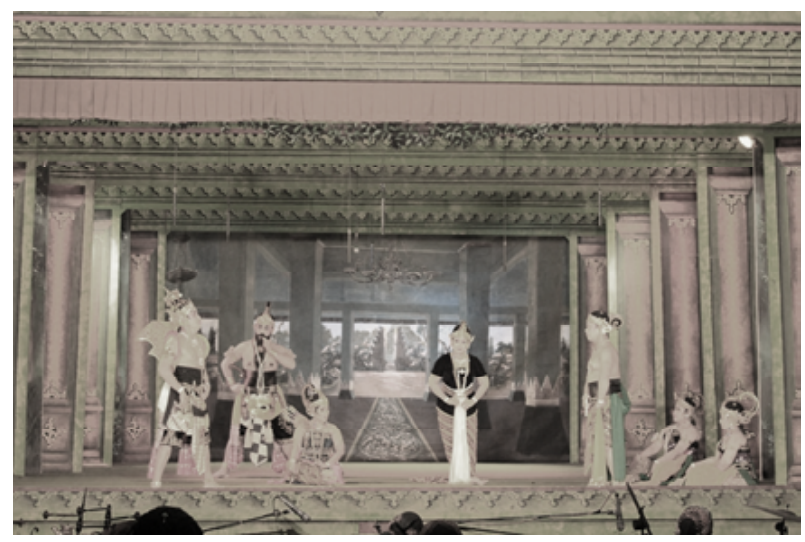

Gambar 2. Pertunjukan wayang orang, sutradara Djaka Harjanto sedang memberi arahan pada pemainnya.(Foto M.Alifi, 2012)

Keyakinan pemain dalam memerankan karakter tokoh wayang orang menentukan cara mengambil sikap dalam menghadapi kisah peristiwa yang terjadi. Sutradara Djaka Harjanto memahami keyakinan pemain terhadap karakter tokoh wayang orang diketahui berhubungan dengan cara beraksi terhadap keadaan pertunjukan. Sutradara menegaskan motivasi membimbing keyakinan difungsikan untuk menyelesaikan masalah-masalah yang dihadapi di atas panggung, semakin yakin pemain menggunakan karakter wayang orang semakin baik penyelesaian yang dilakukannya.

Sutradara memupuk tingkat keyakinan pemain wayang orang dengan kepercayaan diri. 


\section{GE[AR Jumal Sori Bublya}

Kepercayaan diri pemain wayang orang penting ditingkatkan agar pemain lebih menjiwai perannya. Penjiwaan pemain wayang orang terhadap karakter tokoh akan tertuju pada suatu peristiwa di atas panggung yang akan dibuat seindah mungkin. Penjiwaan pemain dengan tokoh wayang orang membuat dirinya terkait dan terikat dengan karakter tokoh tersebut. Dengan sendirinya kepercayaan diri pemain wayang orang mengarahkan penjiwaan pemain kepada tokoh.

Keberhasilan pertunjukan wayang orang dalam hal semangat menjadi tokoh sangat dipengaruhi pada kejiwaan pemain. Tingkat keyakinan dapat meningkatkan penjiwaan pemain terhadap tokoh dan keberhasilan pertunjukan wayang orang. Ketika pemain dan penonton dapat merasakan keharuan, ketegangan, kengerian, menggemaskan, dan keindahan, di situlah letak keberhasilan pertunjukan wayang orang. Berhasilnya pertunjukan wayang orang sangat ditentukan oleh para pemain, sedangkan keberhasilan pemain ditentukan oleh penjiwaannya dalam memerankan tokoh wayang orang. Sutradara Djaka Harjanto memupuk tingkat keyakinan pemain wayang orang dengan kepercayaan diri merupakan tindakan yang sangat tepat.

\section{Peran Sutradara Sebagai Pengarah}

Kekuatan dari ciri khas tokoh wayang orang merupakan dasar dari kegiatan pertunjukan wayang orang. Latihan pertunjukan wayang orang difungsikan untuk mengarahkan pemain dengan ciri khas tokoh wayang orang. Ciri khas tokoh wayang orang sering sekali berhubungan dengan watak, keselarasan penampilan watak pemain wayang orang menggunakan karakter tokoh wayang orang karena pengaruh dari arahan sutradara. Pengarahan sutradara diberikan pada pemain karena kekuatan, ketekunan, kemampuan, dan kepercayaan diri pemain.

\section{KEPUSTAKAAN}

Anirun, Suyatna. Menjadi Sutradara. Bandung: STSI Press, 2002.

Hersapandi. Wayang Wong Sriwedari; Dari Seni Istana Menjadi Seni Komersial. Yogyakarta: Yayasan Untuk Indonesia, 1999.

. Rusman antara Magnit Bung Karno dan Kharisma

Gathutkaca Wayang Orang Sriwedari. Yogyakarta: ISI Yogyakarta, 2011.

Hadiprayitno, Kasidi. Teori Estetika Untuk Seni Pedalangan. Yogyakarta: Lembaga Penelitian Institut Seni Indonesia Yogjakarta, 2004.

Soedarsono, R. M. Wayang Wong; Drama Tari Ritual Kenegaraan di Kraton Yongyakarta. Yogyakarta: Gadjah Mada University Press, 1990. 